\title{
Teachers of Russian Higher Educational Institutions in the Professional Labor Market
}

\author{
Irina Ilina, Elena Kryukova, Alexandra Zotova, Elena Kuznetsova \& Evgeniya \\ Nakhratova \\ Russian State Social University, Moscow, Russia
}

\begin{abstract}
The article analyses the relative position of the Russian teachers from higher education institutions in professional labor market in transition. The specificity of teachers' situation in the labor market is revealed in conditions of shift from administrative command system to market relations. There are some distinguished factors that increase the risk of job loss by teachers of different categories. The characteristics of main forms and types of "professorate" unemployment in modern stage are discussed. Based on the results of sociological survey, the relation of teachers to the market economy is analyzed and an attempt is made to find out the way which can stabilize teachers' professional position at the time when new educational policies are being implemented in order to optimize the field of higher education.
\end{abstract}

Keywords: Labor market, academic teachers, unemployment, employment, higher school upgrading.

\section{Introduction}

In the beginning of the $21^{\text {st }}$ century, the contradictions in higher education in Russia are more obvious. On the one hand, academic teachers, as a social professional group, have the significant scientific potential, special social pedagogical functions, playing an important role in the increase of cultural educational level of the population. However, on the other hand, the modern academic teaching staff of the higher educational institutions is characterized by low life level and quality, the lack of motivation to scientific innovative activity and uncertainty of social status.

In the last several years, the position of teachers has become more complicated. Beginning from 2012, the Russian educational community actively discusses new problems of native higher school - destabilization of professional labor market and growth of unemployment among the academic teachers. In conditions of rapid increase of requirements to the teachers and forced optimization (reduction, in fact) of staff, the academic teachers, even with the highest qualification of Ph.D and D.Sc, lose their job.

The problems of professional labor market have become more urgent in conditions of upgrading the higher educational system in many countries with market economy. Thus, the experts note the decline of situation of academic teachers at the USA and European labor market (El-Khawas, 2010; Musselin, 2013; Stocum, 2013) and reveal the negative dynamics of pay level and labor conditions of teachers (Ouardighi et al., 2013; Alen, 2010; Rambly et al., 2010). The studies, carried out in the last years, testify that Russia, as well as the other countries with market 
economy, is characterized by growth of negative tendencies in staff sphere of higher education. Many Russian scientists also pay attention to the significant adaptation problems of Russian teachers to new conditions (Artamonova, 2008; Gokhberg et al., 2011; Ilyina, 2013; Popova O.I., 2012). However, at present the situation at the professional labor market of academic teachers has not become the subject of serious scientific discussion.

\section{Procedure}

The necessity in complex analysis of processes, taking place at the professional labor market of teachers, has conditioned the active use of different scientific methods. Such general scientific methods, as structural and factor analysis and system approach, are used in the work. The methods of typological, historical, genetic, comparative, micro- and macroeconomic analysis are also used.

The empiric base rests on complex use of the results of economic statistical and sociological studies. The work provides the data of official statistics, presented by the Federal State Statistics Service of Russia (Rosstat), and the data, obtained in the course of monitoring of educational sphere, executed by the National Research University "The Higher School of Economics" (Science Indicators, 2015; Education in Numbers, 2013; Education in Russian Federation: 2014). The empiric base of study is constituted by the results of sociological survey of teachers of the Russian State Social University (RSSU), carried out in the period from 2009 to 2011 under the project "The Development of theoretical and practical bases for motivation and stimulation of academic teachers staff of the higher school in modern conditions", and also the results of sample interview with RSSU teachers in 2015.

The normative legal documents of the Department of Education and Science of RF (a Conception) are used in the work.

The collection, accumulation and generalization of information, reflecting main tendencies of labor market of the academic teachers, provides an opportunity to create the basis for further deeper analysis of problems of the higher school development in modern conditions.

\section{Results}

\subsection{The status of teachers of the Russian higher educational institutions in conditions of administrative command economy}

In the USSR, the profession of teacher was one of the most honorable. The teachers presented a socio-professional group, on which the society imposed an urgently important mission - not just give knowledge, but encourage personal socialization of the student at the important stage of its formation, connected with vocational training, taking into consideration the specificity of training the individuals with disabilities and deviant behavior (Vinogradova at al., 2014). High status positions of the academic teacher were obviously proved by rather high level of labor payment and various privileges, for instance, shortened working day, long vacations, additional square meters of living space for the room etc.

The average wages of the academic teacher constituted approximately $300 \%$ from the average wages in the wider economy, and the one of the starting young teacher was $110-120 \%$. (The Future of the Higher Education, 2013, p. 87). Non-monetary forms of material 
encouragement were of great significance. According to the data of sociological survey, the half of teachers periodically received non-monetary material reward as incentive for working hard.

During few decades, the number of academic teacher has been constantly increasing. Thus, in the period from 1980 to 1989 , the number of academic teachers in the USSR increased from 356.8 thousand up to 379.6 thousand (including Russian higher educational institutions, where it increased from 204.0 to 212.0 thousand people) (Public Education and Culture in the USSR, 1989, p.20)

Obviously, the academic teacher was in stable situation at the labor market. At practically full employment, typical of administrative command economy, the risk of unemployment for highly experienced academic teachers, particularly with science-degree and title, was kept to a minimum level. Officially, a labor contract with a teacher was signed on a competitive basis for the fixed date (frequently, for the several years), but in practice the contract was prorogated without extra formalities for many times.

The level of teachers' professional mobility was low. Long standing in one higher educational institution was of special value. Certainly, the teachers had great opportunities of professional qualified growth under inter-academic labor market. However, the significant part of teachers practically did not have motivation to increase their scientific qualification - judging by the inquiries, $21 \%$ of respondents, holding the position of Assistant professor (with Ph.D.), had no drive for changing their professional qualification status; many teachers without scientific degree also had "frozen" motivation (Mnukhina, 1990).

Russian investigators evaluate the status of academic teacher in administrative command economy in the following way: "The position of professor at the national labor market is determined as follows: high (or sufficient) reward plus high degree of freedom under the labor contract - in exchange for very high (unique or highly specific) qualification level. Until the labor price was enough high, the universities did not feel the lack of young people, ready to follow this way..." (Contracts in Academic World, 2011, p. 13).

\subsection{The dynamics of structural and motivational characteristics of academic teachers in conditions of shift to market relations}

In the beginning of $21^{\text {st }}$ century, the system of Russian higher education was being developed rather actively. Total number of teachers of state and municipal higher educational institutions increased in the period from 2000-2001 to 2012-2013 academic year by 1.8 times, and the number of teachers of non-state higher educational institutions increased more than twice (Education in numbers: 2013, Education in Russian Federation: 2014). However, in last years, the situation began to change, and the number of teachers, working in state and municipal higher educational institutions reduced by 8\%. (Kryukova et all, 2014; Maloletko, et all, 2015).

The professional qualified parameters of the teaching community have been transformed. If in 2000-2001 academic year each tenth teacher of the state or municipal higher educational institution had a Sc.D, then in 2005-2006 academic year the Sc.D teachers constituted less than $11 \%$ from total number, and in 2011-2012 - 12.5\%. The share of Ph.D teachers also changed; in 2000-2001 they constituted $47.2 \%$ from the professor teaching staff of the state and municipal higher educational institutions, and in 2011-2012 - more than 53\%. At present, $13.7 \%$ of teachers have the Sc.D, and $54.7 \%$ have the Ph.D (Indicators of Science, 2015).

In the period of active transformations in Russian higher school, motivational characteristics of academic teachers have changed significantly. Different sociological survey, 
carried out in the last decades, fixed not only stable decay of life level and quality, but also sheer "fall" of social-professional status of teachers. More than 4/5 of respondent teachers mentioned unacceptably low level of labor payment, $70-75 \%$ confessed, that they have to have a side job, because it is impossible to survive on the salary. The average monthly wage of Russian teachers per one job place in the beginning of 2000 was nearly USD 75-90. Only in Moscow the teachers' average wage per the main job increased USD 100 (Artamonova, 2008).

Contradictory moods emerged in the teachers' sphere. On the one hand, a significant part of teachers tried to support the traditional prestige of profession, noting, that even in difficult economic situations, they feel proud for their professional activity. On the other hand, there was a growing dissatisfaction in policy, carried out in the sphere of higher education, the doubts in correctness of the selected strategy for the higher school development increased. Typical statements, obtained in the course of teachers' inquiries were the following:

"I'm proud that I'm an academic teacher in 4 th generation, BUT!!! I feel hurt by the state's relation to the pedagogical activity";

"I like to teach, but I understand the non-prestigious and labor intense character of my profession. I'm pleased that my children chose another way";

"Modern bureaucratic system in education impedes my idea of the role and tasks of teachers" (Popova O.I., 2012).

Thus, the years of active market transformations have become a serious trial for Russian academic community. However, till present, the professional academic market differed by relative stability.

\subsection{The reasons of destabilization of professional labor market of the academic teachers at the modern stage}

The main reason of degradation of situation at the professional labor market of the academic teachers is the "optimization" politics, carried out by Russian Ministry of Education and Science. One of the purposes of this policy is to reduce the number of higher educational institutions in the country, which results in reduction of number of teachers and intensification of competition at the professional labor market. Such approach was conditioned not only by the necessity to get the sphere of higher education under control. The reduction of number of higher educational institutions is mainly connected with the "demographic pit", which swallowed the system of higher education in the last 3-5 years. The significant reduction of birth rate in the 1990s resulted in significant reduction of people, finishing schools and entering the higher educational institutions. The condition of the Russian economy in 2014-2015 also had a definite influence on the sphere of higher education. The reduction of budget made the Ministry of Education and Science to tighten the requirements to the state higher educational institutions, forcing them to reduce personnel costs.

Still in 2010, the Ministry of Education and Science of RF provided the calculations, according to which nearly 100 thousand academic teachers can become unemployed. According to the specialists' estimation, each "fourth" entered the risk zone (Druzhilov, 2011). According to the "Concept of Federal Target program of Education Development for the period from 2011 to 2015", it was forecast that the general number of students would reduce by more than $40 \%$ as compared with the number of students in 2009. Respectively, it was expected, that the number of academic teaching staff would reduce by not less than $20-30 \%$ (A Concept).

In conditions of sharp intensification of competition at the labor market, the average Russian professor became quite defenseless due to number of reasons: 
- a habit of stable life;

- a feeling of relative freedom due to lack of rigid requirements to professional activity and insufficient control on the part of administration of the higher educational institutions;

- $\quad$ low level of labor mobility (absolute non-readiness to territorial mobility);

- the presence of significant theoretical knowledge with obvious shortage of practical experience (i.e. the lack of experience in labor activity and useful contacts outside the higher school);

- $\quad$ the lack of "commercialization knowledge" culture, i.e. skills and abilities to turn your intellectual capital into real money (at that, with non-criminal methods);

- the lack of skills of competitive struggle for the work space, insufficient legal literacy, not allowing to protect the rights properly in dispute with the employer;

- assurance in the fact, that high professional qualification status (Ph.D or Sc.D) is the life-time warranty to be in demand in the system of higher education.

\section{4. "Professorate unemployment" as a new social economic phenomenon}

Obviously, "professorate unemployment" is a new phenomenon for modern Russia. Insufficiency of data of official statistics does not allow evaluating the problem to the full extent. However, the analysis of main tendencies of professional labor market of teachers provides an opportunity to distinguish several types of "professorate unemployment" (Ilina et al., 2014; Ilina et al., 2015;).

\section{Frictional unemployment}

It is present at any time and at any system of economic relations. It appears, when the teacher leaves one job place at his own request to find another one. Sometimes, the quit bears a remonstrative character, i.e. the teacher expresses his disagreement with the policy of the academic administration. The problem is that the period of new job search in conditions of total reduction of higher institutions becomes rather long. Moreover, there is no guarantee that the problem of employment will be solved.

2. Structural unemployment

At present, it is the most common type of unemployment in the sphere of higher education. Teachers' job loss is frequently connected with restructuring and optimization of the academic system. For instance, the structure of programs is being changed, weak higher educational institutions are joined to stronger ones or even closed down.

The specialists of humanitarian and social sciences found themselves in especially difficult situation. According to the plans of the Ministry of Education and Science of RF, first of all, the students training on economy and jurisprudence shall be reduced.

\section{Reputational unemployment}

It is a new type of unemployment for Russia, connected with scandal disclosure of people, involved into preparation and defense of dissertations with the significant plagiary part. The professors' community treats the victims of "antiplagiarism" campaign differently, but the teachers with spoilt reputation have difficulties in finding a new job in the higher educational institution. At that, it refers not only to those, who were deprived of the science degree with shame, but also those who were involved into the process of dissertation defense. Prestigious institutions prefer not to deal with participants of scandal "antiplagiarism" disclosures.

\section{Hidden unemployment}

It is not a new type of unemployment, but recently it becomes more expanded. In this situation, the teacher, trying to hold his/her job, is to agree for the part-time work. Elderly 
people (7o years and more) or other vulnerable categories of workers (for instance, with low indices of publication activity) are usually found themselves in such situation. There is a risk that in conditions of strengthening competence at labor market, the probability of discrimination manifestations in relation to different categories of academic teachers will increase.

The peculiarity of "professorate unemployment" in Russia is, first of all, its latent character. The academic teachers, who lost their job, practically never go to the Government Employment Service (GES). It means that they do not get the official standing of 'unemployed'. The unemployed teacher prefers finding a new job by means of friends, at least, by means of Internet. Although the last variant, with all its availability and efficiency, does not suit in this case. Rare job advertisements for academic teachers are usually placed by the dingy commercial higher educational institutions with not very favorable work terms (part-time work is suggested most commonly). Private employment patterns (recruiting agencies) are not also in a hurry to participate in employment assistance of jobless teachers, as the higher educational institutions are not considered to be beneficial customers.

\subsection{The evaluation of situation at the professional labor market: the teachers' opinion}

The results of inquiries of teachers in Russian State Social University (RSSU), carried out in the period from 2009 to 2011, and also sample interview, held in 2015, provide an opportunity to reveal the teachers' opinion about the situation at professional labor market.

According to the data of social inquiry, still in 2009, many teachers considered their situation unstable. $2 / 5$ of respondents assumed, that they could lose their job in the university at any time. However, the share of those, who felt secure at their job places exceeded - $45.3 \%$ of respondents states, that they are on safe ground from job loss. Age-related and professional qualification characteristics of workers conditioned the differentiation of replies. The teachers of active age (25-45 years) with the science degree (Ph.D and especially Sc.D) were more confident in the stability of their position.

In 2015 , the situation has significantly changed. In the course of survey, it was found out, that the academic teaching staff of the RSSU were united in their opinion. Absolutely all respondent teachers note that job loss in modern conditions is quite real. Even the teachers with the highest professional qualification status (Sc.D degree) are not the exception. At that, nearly $3 / 4$ of respondents are sure that they will face hard difficulties in searching for the job at the professional labor market.

In the period from 2009 to 2015, the possibilities of teachers to work in the other institutions have reduced sharply. Although the share of the desirous remains quite stable (nearly $1 / 3$ of respondents), many teachers have no real conditions to get stable extra income.

The reduction of protection level is typical of teachers' professional market. Still in 2009, more that $64 \%$ of respondent teachers noted that recently the level of social protection of institution workers reduced. The majority of teachers admitted this fact in 2015. At that, the majority was sure that the reduction of social protection level of the workers presents a general tendency, typical of the majority of companies of social sphere of the Russian labor market.

Positive tendencies, revealed in the last survey, involve activation of the teachers' research activity. Practically all respondents note the necessity to increase their competitive ability at the professional labor market due to the improvement of basic indices of research activity. 
General social psychological climate is characterized by the domination of negative expectations both at the level of definite teams (for instance, expectations of income decay), and at macrolevel (risks, conditioned by general social-economic instability).

\subsection{Ways to stabilize the situation at the professional labor market of academic teachers}

Stabilization of professional labor market in modern conditions is one of the main tasks of the higher school, the solution to which is being expected not only by thousands of academic teachers throughout the whole country, but also by everyone, who is interested in successful development of higher education system in modern Russia.

High-priority directions to stabilize the situation at the professional labor market of academic teachers can be the following:

i. To elaborate and to specify the plans of the Ministry of Education and Science on optimization and restructuring of institutions. Planned indices of reduction of number of academic teachers shall be thoroughly calculated, substantiated and presented to the academic community.

ii. To increase the level of social protection of academic teachers at the labor market in the situation of planned reduction of number of academic teaching staff.

iii. To increase the activity of sectoral union to protect teachers' interests, especially those, who are in "risk group".

iv. To develop a clear system of evaluation criteria for professional activity of the academic teacher. This system shall be common for the institutions of similar specialization (for instance, for classical universities, technical institutes etc.).

v. To organize not formal, but real competitions to fill the vacancies of academic teaching staff, strictly on the basis of the developed criteria.

vi. $\quad$ To shift to individual "effective contracts" for each teacher; these documents shall define all requirements of the institution to the worker.

vii. To develop and to implement the effective mechanism of material and non-material motivation, taking into consideration a wide spectrum of indices of academic and scientific activity of teachers.

viii. To create the conditions for civilized competition at the professional market for academic teachers, following all rules of the RF Labor Code.

ix. To form the conditions to increase the inter-institutional mobility of teachers on the basis of cooperation agreements between the institutions, including the ones at interregional and international level.

x. To hold a monitoring of situation at the professional labor market of academic teachers with participation of speakers of the Ministry of Education and Science, mass media and trade unions.

\section{Discussion}

In recent years, Russian educational community actively discusses many urgent reforming problems of higher education. The significant tightening of requirements of the society to the higher school, as well as sharpening of competition in the professional sphere, conditioned cardinal changes at the labor market of academic teachers. In this connection, the discussion of relevant tendencies and directions of transformation of teachers' professional labor market causes great interest in the educational community. Separate provisions of the undertaken study were reported and actively discussed in different scientific conferences. In particular, the dynamics and differentiation of teachers' professional market in the period of modernization of the higher 
school were discussed in the course of the XIV All-Russian Social Pedagogical Congress, that took place in the RSSU on June 5-6, 2014. The most urgent tendencies and adaptation problems of the educational community to new social economic conditions have become the subject of discussion at the Social Congress on November 25-26, 2014. In the course of the discussion, it was noted, that the deformation of teachers' professional labor market and growth of "academic unemployment" are conditioned by not only objective reasons and crisis phenomena in Russian economy. Negative factors, worsening the position of teachers, are the low level of professional mobility and insufficient scientific-innovative activity of the teacher's community. Obviously, many basic values of scientific career are being destroyed at the modern stage - stability of situation, full employment, long-term connections with one institution etc. Many teachers perceive the refusal from former standards of professional activity very painfully; it complicates the solution of problems of professional labor market of academic teachers.

The authors prepared a number of publications in Russian and Foreign Science Magazines for this topic (Ilina, 2013; Ilina et al., 2014).

\section{Conclusion}

At the modern stage, there is a process of accumulation and systematization of theoretical and empirical material on the problems of labor market of Russian academic teachers.

Undoubtedly, the study reveals not all aspects of transformation of educational sphere and development of professional labor market. We consider that the perspective direction to study the relations in the sphere of labor and employment of academic teachers is the evaluation of social psychological aspects of adaptation of the educational community to new requirements. The need in such work is conditioned by the fact that in conditions of increasing negative tendencies at the labor market, indeterminacy and instability of teachers strengthens. Social psychological strain in work results in open and hidden conflict situations, giving birth to professional destructive behavior and simply unethical practices. In these conditions, the development of recommendations on minimization of negative consequences of the accepted management solutions - not only of theoretical, but also of practical importance, will provide an opportunity to improve motivational and social psychological climate in higher educational institutions.

At present, the existing situation at professional labor market of academic teachers requires special attention, because the history of Russian higher education lacks the experience in solution to such problems. At present, it is hardly possible to rely on ambitious protests and consolidated movement of teachers in conditions of forthcoming dismissals. It is obvious that dissociation, perplexity and lack of interest of the academic teaching community in transformations are the reasons that hinder significantly the development of Russian educational sphere in our times.

\section{References}

"Concept of Federal Target program of Education Development for the period from 2011 to 2015"

El-Khawas, E., (2010). Human Resource Issues in Higher Education, in International Encyclopedia of Education (3d ed.). Penelope Peterson, Eva Baker and Barry McGaw (Eds.) Elsevier, Oxford, 527-532.

Ilina, I.Yu., Belotelova, N.P., Danilina, E.I., Novikova, D.M., Pochinok, N.B. (2014). "Professorate unemployment" in modern Russia. Asian Social Science, 10. 24, 217-223. 
Ilina, I.Y., Kryukova, E.M., Zotova, A.I., Chardymskiy, M.G., and Skudareva, N.Z. (2015). Scientific degrees as a status characteristic of Russian university teachers. International Education Studies, 8, 5, 165-171. DOI: 10.5539/ies.v8n5p165

Kryukova, E.M., Makeeva, D.R., and Konovalova, E.E. (2014). Tourism as preferred direction in the strategy of substitution of industry branches in mono-territories of Russian Federation. World Applied Sciences Journal, 1, 30, 176-178. DOI: 10.5829/idosi.wasj.2014.30.mett.24

Maloletko, A.N., Kaurova, O.V., Kryukova, E.M., Pochinok, N.B., and Gladko, E.A. (2015). Analysis of key indicators of tourism industry in Russia. Modern Applied Science, 9 (3), 25-33. DOI: 10.5539/mas.v9n3p25

Musselin, C. (2013). How peer review empowers the academic profession and university managers: Changes in relationships between the state, universities and the professoriate. Research Policy, 5 (42), 1165-1173.

Ouardighi, F., Kogan, K., and Vranceanu, R. (2013). Publish or teach? Analysis of the professor's optimal career path. Journal of Economic Dynamics and Control, 10 (37), 1995-2009.

Stocum, D. L. (2013). Killing Public Higher Education: The Arms Race for Research Prestige, In Killing Public Higher Education. David L. Stocum (Ed.). Academic Press, Boston, 1-36.

Vinogradova, M.V., Kryukova, E.M., Kulyamina, O.S., Vapnyarskaya, O.I., and Sokolova, A.P. (2014). Approaches to the study of the status and trends of drug abuse, rehabilitation and reintegration of drug users. Biosciences Biotechnology Research Asia, 11(3), 1505-1514. DOI: 10.13005/bbra/1545

Artamonova, M.V. (2008). A reform of the higher school and Bologna process (private view of the methodist). M.: Economy Publisher.

Future of the higher education and academic profession: the BRIC countries and the USA (2013). M.: National Research University "The Higher School of Economics".

Gokhberg, L.M., Zaychenko, S.A., Kitova, G.A. and Kuznetsova, Yu.E. (2011). Science policy: Global context and Russian practice. M.: National Research University "The Higher School of Economics".

Druzhilov, S.A. (2011). Demographic "pit" and the threat of unemployment of academic teachers. Modern Science Studies and Innovations, 7. Retrieved on July 24, 2014 from http://web.snauka.ru/issues/2011/11/5325

Ilina, I.Yu. (2013). Science investigative activity of academic teachers and ways of its activation. Human Capital, 2 (50).

Science indicators 2015: Statistical Collection (2015). M.: National Research University "The Higher School of Economics".

Contracts in academic world (2011). M.M. Yudkevich (Ed.). M.: National Research University "The Higher School of Economics".

Mnukhina, T.A. (1990). Social mobility of science pedagogical staff of the high school (Doctoral dissertation). M.: MSU, 09.00.02.

Public education and culture in the USSR: Statistical collection (1989). M.: Finances and statistics.

Education in Russian Federation: Statistical collection (2014). M.: National Research University "The Higher School of Economics".

Education in figures: 2013: Brief statistical collection (2013). M.: National Research University "The Higher School of Economics".

Popova, O.I. (2012). Academic teacher: modern view on profession, experience of sociological study. Pedagogical education in Russia, 6.

Rambly, L.E., Pacheko, I.F. and Altbakh, F.J. (2010). International juxtaposition of labor payment of academic teachers. Education Economics, 1. 